\title{
Eggerthella lenta bacteremia successfully treated with ceftizoxime: case report and review of the literature
}

\author{
Shuming Jiang ${ }^{1 \dagger}$, Jianfei $E^{2 \dagger}$, Dengchao Wang ${ }^{2}$, Yanjiao Zou², Xiao Liư ${ }^{2}$, Hualiang Xiao ${ }^{2}$, Yuan Wen ${ }^{2}$ and \\ Zongyao Chen ${ }^{2^{*}}$ (D)
}

\begin{abstract}
Eggerthella lenta is a normal human microflora that is anaerobic, non-sporulating, and Gram positive. However, an increasing number of studies have shown that it could also be an important pathogen for humans, even causing lifethreatening infection under certain conditions. However, understanding its pathogenic mechanism and treatment options still need to be improved; more clinical data are needed to explore it further. In this article, we report a case of ceftizoxime-cured E. lenta bacteremia and review the recent literature to provide more clinical data for the diagnosis of E. lenta bacteremia. Our report suggests that the frequency of E. lenta bacteremia is increased in patients with hematologic or solid organ cancer, diabetes mellitus and also in those with appendicitis.
\end{abstract}

Keywords: Eggerthella lenta, Bacteremia, Ceftizoxime, Appendicitis

\section{Introduction}

Eggerthella lenta was first described by Arnold Eggerth in 1935 [1], which was originally named Eubacterium lentum. E. lenta is a normal bacterium that can colonize the human gut, female reproductive tract, oral cavity, and prostate gland [2]. Due to the nature of strictly anaerobic and slow growth, E. lenta is difficult to culture and identify. Although, until recently, several microbial identification techniques, particularly mass spectrometry, were used to identify bacteria [3, 4], an increasing number of $E$. lenta infections in humans have been reported, referring to bloodstream infection [5-7], liver abscess [8], bacterial vaginosis [9] and meningitis [10]. However, a unified standard treatment and its pathogenic mechanism have not yet been recognized. Here, we report cases of E. lenta bacteremia cured by ceftizoxime and review

\footnotetext{
*Correspondence: chenzyao@yeah.net

${ }^{\dagger}$ Shuming Jiang and Jianfei E contributed equally to this work

${ }^{2}$ Department of Clinical Laboratory, People's Hospital of Deyang City, Deyang, China

Full list of author information is available at the end of the article
}

the existing recent literature. This article aims to add to existing data for the timely diagnosis and treatment of $E$. lenta bacteremia.

\section{Materials and methods Case presentation}

A 32-year-old man was admitted to our hospital with metastatic right lower abdominal pain for more than $20 \mathrm{~h}$. He had a healthy history. On admission, he had fever $\left(39.8{ }^{\circ} \mathrm{C}\right)$, laboratory tests showed elevated C-reactive protein $(127 \mathrm{mg} / \mathrm{L})$, elevated white blood cell count $\left(20.67 \times 10^{9} / \mathrm{mL}\right.$ with $87.3 \%$ neutrophils $)$, elevated procalcitonin $(0.95 \mathrm{ng} / \mathrm{mL})$ and normal biochemical and coagulation parameters. Color Doppler ultrasound suggested appendicitis. Two sets of blood cultures (four blood culture bottles) were consecutively taken and incubated for pathogenic detection before the use of ceftizoxime ( $3 \mathrm{~g}$, ivgtt, q8h) in empirical anti-infective therapy. The patient underwent an appendectomy. The patient's temperature and white blood cell count gradually dropped to original author(s) and the source, provide a link to the Creative Commons licence, and indicate if changes were made. The images or other third party material in this article are included in the article's Creative Commons licence, unless indicated otherwise in a credit line to the material. If material is not included in the article's Creative Commons licence and your intended use is not permitted by statutory regulation or exceeds the permitted use, you will need to obtain permission directly from the copyright holder. To view a copy of this licence, visit http://creativecommons.org/licenses/by/4.0/. The Creative Commons Public Domain Dedication waiver (http://creativeco mmons.org/publicdomain/zero/1.0/) applies to the data made available in this article, unless otherwise stated in a credit line to the data. 
normal 2 days later, but procalcitonin was still abnormal $(0.35 \mathrm{ng} / \mathrm{mL})$.

Blood culture (two anaerobic bottles) appeared positive in the BacT/ALERT 3D blood culture system (bioMerieux, France) for 49.8 and 56.0 h, respectively. Furthermore, positive broth culture was incubated in an anaerobic airbag (bioMerieux, Lyon, France) for $72 \mathrm{~h}$, and small transparent gray colonies can be seen. The isolated strain was identified as Eggerthella lenta with the help of MALDI-TOF (Bruker Daltonik GmbH, Germany), with a value of 2.08, indicating a high confidence result. Additionally, 16S rRNA sequencing was performed to further confirm the precision of our identification. The result showed that our strain had the highest identity with the Eggerthella lenta DSM 2243 strain. The result of $16 \mathrm{~S}$ rRNA sequencing was submitted to the NCBI database with accession number MW295842.

From the results of the microbiological examination, the clinicians believed that the current antibacterial agent (ceftizoxime) is effective and should not be replaced. Seven days after surgery, the patient recovered and was discharged from the hospital.

\section{Literature search}

We searched the literature in PUBMED from 2000 to 2020, using the search terms "eggerthella lenta and bacteremia" or "eggerthella lenta and blood". From the retrieved literature, we selected the literature with a detailed description of the case and summarized the patient's clinical characteristics.

\section{Discussion}

In recent years, Eggerthella lenta has received increasing attention as a human pathogen. However, due to its fastidious nature, some cases of $E$. lenta infection could previously have been undiagnosed by conventional biochemical methods [11]. Methods such as $16 \mathrm{~S}$ ribosomal RNA (16S rRNA) gene sequencing techniques were considered the most accurate method. However, this method is costly and may not be readily available. Newer methods, such as MALDI-TOF MS, can quickly identify $E$. lenta and are more readily available at relatively low cost [4].

Several reports have shown that $E$. lenta can be isolated from humans at multiple sites [12-15], which presented a greater challenge for its clinical diagnosis and treatment. Recent research has attempted to summarize the determinants of E. lenta bacteremia. An earlier study showed that most $E$. lenta bacteremia exhibited serious intraabdominal pathology [16]. Our case, the patient admitted to the hospital due to appendicitis, was also consistent with this observation. E. lenta, which colonizes the intestinal tract, could easily invade the bloodstream through the damaged mucosa and cause bacteremia. However, other studies showed that patients with cancer, decubitus ulcers, and diabetes mellitus were more likely to suffer from $E$. lenta bacteremia $[17,18]$. All of these investigations showed different results due to the different populations involved.

We summarized 175 patients with $E$. lenta bacteremia from the literature $[5-7,10,19-31]$, along with the case reported here. The clinical characteristics of these 176 cases in total are presented in Table 1. Males (102/176) and individuals around 60 years of age (mean age $=61.2$ ) were highly likely to be infected with $E$. lenta, while $63.3 \%$ had fever, $46.7 \%$ abdominal pain, $27.8 \%$ vomiting, and $16.1 \%$ diarrhea. This suggests that about $36.7 \%$ of the patients did not show fever symptoms in the case of $E$. lenta bacteremia, making it a great challenge for clinicians to accurately diagnose the bloodstream infection caused by this bacillus. Our data showed that the most common underlying health conditions for E. lenta bacteremia were solid or hematologic organ cancer (31.1\%), diabetes mellitus (25.6\%), and cardiovascular diseases (15.0\%). These three conditions represented $71.7 \%$ of the total of 176 patients, while the main sources of infection in all of these patients were the gastrointestinal tract (65.0\%), skin and soft tissues (19.4\%), and abscess (8.9\%). Of all initial symptoms, appendicitis accounts for the highest proportion, $21.8 \%$, much higher than colitis, the second largest, 9.4\%. Appendicitis is often accompanied by perforation or even peritonitis. E. lenta, normally colonized in the gastrointestinal tract, could invade the bloodstream more easily. Therefore, patients with tumors, diabetes mellitus, and appendicitis should pay more attention to bloodstream infection by E. lenta.

The most efficient antibacterial drugs against $E$. lenta infection are metronidazole, amoxicillin-clavulanate, and carbapenems; it is resistant to ceftriaxone [7, 16, $18,20,32]$. Our patients empirically used ceftizoxime without clear pathogenic bacteria and showed good efficacy, which to our knowledge, has not been reported so far in the literature. Although both ceftizoxime and cefotaxime belong to the third generation of cephalosporins, ceftizoxime has a higher antianaerobic activity than cefotaxime [33], which may be the reason why our patients have a better response to ceftizoxime. However, there could be other reasons. An earlier study divided 29 patients infected with E. lenta into two groups and found one susceptible to beta-lactam drugs, while the other was completely resistant to beta-lactam antibiotics [34]. From this, we could speculate that our strain belonged to the group that was sensitive to beta-lactam antibiotics. It was unfortunate that we were unable to perform antimicrobial susceptibility tests due to the limitations of our conditions. Although more tangible evidence is needed to 
Table 1 Clinical features of 176 patients with E. lenta bacteremia

\begin{tabular}{|c|c|c|}
\hline Characteristic & Number of patients & Percentage (\%) \\
\hline Male/female & $102 / 74$ & - \\
\hline Mean age, year & $61.6(19-86)$ & - \\
\hline \multicolumn{3}{|l|}{ Presenting symptoms at admission } \\
\hline Fever & 114 & 63.3 \\
\hline Abdominal pain & 84 & 46.7 \\
\hline Emesis & 50 & 27.8 \\
\hline Diarrhea & 29 & 16.1 \\
\hline \multicolumn{3}{|l|}{ Underlying health status } \\
\hline Hematologic or solid organ cancer & 56 & 31.1 \\
\hline Diabetes mellitus & 46 & 25.6 \\
\hline Cardiovascular diseases & 27 & 15.0 \\
\hline Chronic kidney disease & 19 & 10.6 \\
\hline Dementia & 15 & 8.3 \\
\hline Chronic pulmonary disease & 13 & 7.2 \\
\hline Peripheral vascular disease & 10 & 5.6 \\
\hline Cerebral vascular disease & 9 & 5.0 \\
\hline Liver cirrhosis & 7 & 3.9 \\
\hline None & 7 & 3.9 \\
\hline HIV infection & 6 & 3.3 \\
\hline Rheumatologic disease & 4 & 2.2 \\
\hline Crohn's disease & 1 & 0.6 \\
\hline \multicolumn{3}{|l|}{ Likely source of infection } \\
\hline Gastrointestinal & 117 & 65.0 \\
\hline Appendicitis & 39 & 21.7 \\
\hline Colitis & 17 & 9.4 \\
\hline Diverticulitis & 16 & 8.9 \\
\hline Small bowel obstruction & 9 & 5.0 \\
\hline Colon cancer & 7 & 3.9 \\
\hline Gastrointestinal bleeding & 3 & 1.7 \\
\hline Other & 9 & 5.0 \\
\hline Skin and soft tissues & 35 & 19.4 \\
\hline Decubitus ulcer & 9 & 5.0 \\
\hline Sacral ulcers & 9 & 5.0 \\
\hline Other & 17 & 9.4 \\
\hline Abscess & 16 & 8.9 \\
\hline Intra-abdominal abscess & 10 & 5.6 \\
\hline Liver abscess & 3 & 1.7 \\
\hline Other & 3 & 1.7 \\
\hline Pulmonary & 2 & 1.1 \\
\hline Pancreatitis & 1 & 0.6 \\
\hline Blunt trauma & 2 & 1.1 \\
\hline Bacteremia caused by an unknown source & 24 & 13.3 \\
\hline
\end{tabular}

confirm, our findings also contribute to a better understanding of the resistance characteristics of E. lenta.

To conclude, the frequency of E. lenta bacteremia is increased in patients with hematologic or solid organ cancer, diabetes mellitus and also in those with appendicitis. E. lenta bacteremia in our study was successfully treated with ceftizoxime; however, this needs to be further confirmed in future research. 


\section{Acknowledgements}

Special thanks to the editors and the reviewers for insightful suggestions on this work. We are indebted to Dr. Liangyou Tang for his excellent suggestions on the revision of the manuscript.

\section{Authors' contributions}

ZC and SJ were involved in concept and writing. JE and DW were involved in literature searching and manuscript revision. $Y Z, X L, H X$ and $Y W$ were involved in data analysis. All authors read and approved the final manuscript.

\section{Funding}

Our study was supported by Deyang Science and Technology Program (2018SZS076).

\section{Availability of data and materials}

Not applicable.

\section{Declarations}

\section{Ethics approval and consent to participate}

The case report was approved and supervised by the ethics committee of the People's Hospital of Deyang City.

\section{Consent for publication}

Waiver of informed consent.

\section{Competing interests}

The authors declare that they have no competing interests.

\section{Author details}

'Pathology Department, People's Hospital of Deyang City, Deyang, China. ${ }^{2}$ Department of Clinical Laboratory, People's Hospital of Deyang City, Deyang, China.

Received: 8 April 2021 Accepted: 9 September 2021

Published online: 20 September 2021

\section{References}

1. Eggerth A. The Gram-positive non-spore-bearing Anaerobic Bacilli of human feces. J Bacteriol. 1935;30(3):277-99.

2. Lau S, Woo P, Woo G, et al. Eggerthella hongkongensis sp. nov. and Eggerthella sinensis sp. nov., two novel Eggerthella species, account for half of the cases of Eggerthella bacteremia. Diagn Microbiol Infect Dis. 2004:49(4):255-63.

3. Barreau M, Pagnier I, la Scola B. Improving the identification of anaerobes in the clinical microbiology laboratory through MALDI-TOF mass spectrometry. Anaerobe. 2013;22:123-5.

4. Schmitt B, Cunningham S, Dailey A, et al. Identification of anaerobic bacteria by Bruker Biotyper matrix-assisted laser desorption ionization-time of flight mass spectrometry with on-plate formic acid preparation. J Clin Microbiol. 2013;51(3):782-6.

5. Lee M-R, Huang Y-T, Liao C-H, et al. Clinical and microbiological characteristics of bacteremia caused by Eggerthella, Paraeggerthella, and Eubacterium species at a University Hospital in Taiwan from 2001 to 2010. J Clin Microbiol. 2012;50(6):2053-5.

6. Liderot K, Larsson M, Borang S, et al. Polymicrobial bloodstream infection with Eggerthella lenta and Desulfovibrio desulfuricans. J Clin Microbiol. 2010;48(10):3810-2.

7. Bo J, Wang S, Bi Y, et al. Eggerthella lenta bloodstream infections: two cases and review of the literature. Future Microbiol. 2020;15:981-5.

8. Elias R, Khoo S, Pupaibool J, et al. Multiple pyogenic liver abscesses caused by Eggerthella lenta treated with Ertapenem: a case report. Case Rep Med. 2012;2012:718130.

9. Shipitsyna E, Roos A, Datcu R, et al. Composition of the vaginal microbiota in women of reproductive age-sensitive and specific molecular diagnosis of bacterial vaginosis is possible? PloS ONE. 2013;8(4):e60670.
10. Gardiner BJ, Korman TM, Junckerstorff RK. Eggerthella lenta bacteremia complicated by spondylodiscitis, psoas abscess, and meningitis. J Clin Microbiol. 2014;52(4):1278-80.

11. Jiang J, She B, Zheng R. Bacteremia caused by the Eggerthella lenta in a previously healthy 30-year-old man with acute suppurative appendicitis: a case report from China. Infect Drug Resist. 2020;13:3695-8.

12. Lattuada E, Zorzi A, Lanzafame M, et al. Cutaneous abscess due to Eubacterium lentum in injection drug user: a case report and review of the literature. J Infect. 2005;51(2):E71-72.

13. Bok C, Ng Y. Eggerthella lenta as a cause of anaerobic spondylodiscitis. Singapore Med J. 2009;50(12):e393-396.

14. Moon T, Lin R, Jahn A. Fatal frontal sinusitis due to Neisseria sicca and Eubacterium lentum. J Otolaryngol. 1986;15(3):193-5.

15. Palomino-Nicás J, González E, Arroyo A, et al. Pyomyositis due to Eubacterium lentum and Streptococcus constellatus from a periodontal source. Clin Infect Dis. 1996;22(1):176-8.

16. Gardiner BJ, Tai AY, Kotsanas D, et al. Clinical and microbiological characteristics of Eggerthella lenta bacteremia. J Clin Microbiol. 2015;53(2):626-35.

17. Venugopal AA, Szpunar S, Johnson LB. Risk and prognostic factors among patients with bacteremia due to Eggerthella lenta. Anaerobe. 2012;18(4):475-8

18. Woerther $\mathrm{PL}$, Antoun S, Chachaty $\mathrm{E}$, et al. Eggerthella lenta bacteremia in solid tumor cancer patients: pathogen or witness of frailty? Anaerobe. 2017:47:70-2.

19. Wong D, Aoki F, Rubinstein E. Bacteremia caused by Eggerthella lenta in an elderly man with a gastrointestinal malignancy: a case report. Can J Infect Dis Med Microbiol. 2014;25(5):e85-86.

20. Salameh A, Klotz SA, Zangeneh TT. Disseminated infection caused by Eggerthella lenta in a previously healthy young man: a case report. Case Rep Infect Dis. 2012;2012:1-3.

21. Fatima T, Hasan R, Tariq S. Eggerthella lenta bacteremia in endometrial adenocarcinoma - a case report from Pakistan. J Pak Med Assoc. 2020;70(6):1079-80.

22. Thota V, Dacha S, Natarajan A, et al. Eggerthella lenta bacteremia in a Crohn's disease patient after ileocecal resection. Future Microbiol. 2011;6(5):595-7.

23. Lee HJ, Hong SK, Choi WS, et al. The first case of Eggerthella lenta bacteremia in Korea. Ann Lab Med. 2014;34(2):177-9.

24. Mal P, Rafiq I, Iftikhar I, et al. Pelvic abscess caused by a slow growing anaerobic bacterium, Eggerthella lenta: first case report from Pakistan. J Pak Med Assoc. 2017:67(10):1604-5.

25. Priputnevich T, Lyubasovskaya L, Muravieva V, et al. Postpartum endometritis and obstetrical sepsis associated with Eggerthella lenta. Case report and review of the literature. J Matern Fetal Neonatal Med. 2019:34(2):313-7.

26. Cordoba G, Kim ML, Sharma S, et al. Septic shock caused by the under-recognized bacterium Eggerthella lenta in a 61-year-old male with a periurethral abscess: a case report. Rev Soc Bras Med Trop. 2019;52:e20190081

27. Ugarte-Torres A, Gillrie MR, Griener TP, et al. Eggerthella lenta bloodstream infections are associated with increased mortality following empiric piperacillin-tazobactam (TZP) monotherapy: a population-based cohort study. Clin Infect Dis. 2018;67(2):221-8.

28. Liderot $K$, Ratcliffe $P$, Luthje $P$, et al. Microbiological diagnosis of Eggerthella lenta blood culture isolates in a Swedish tertiary hospital: rapid identification and antimicrobial susceptibility profile. Anaerobe. 2016:38:21-4

29. Jehangir W, Sanabria F, Singh Z, et al. Enteric fistulous communication with an aortobifemoral graft permitting for Eggerthella lenta colonization. J Glob Infect Dis. 2015;7(4):170-2.

30. Elias R, Khoo S, Pupaibool J, et al. Multiple pyogenic liver abscesses caused by Eggerthella lenta treated with ertapenem: a case report. Case Rep Med. 2012:2012:718130.

31. Goupil R, Nadeau-Fredette A, Tennankore K, et al. Peritonitis caused by veillonella species and Eggerthella lenta in peritoneal dialysis. Perit Dial Int. 2014;34(2):245-7.

32. Declerck B, Van der beken $Y$, de Geyter D, et al. Antimicrobial susceptibility testing of Eggerthella lenta blood culture isolates at a university hospital in Belgium from 2004 to 2018. Anaerobe. 2021;69:102348. 
33. Canadian Medical Association. Ceftizoxime: a third-generation cephalosporin active against anaerobic bacteria Committee on Antimicrobial Agents, Canadian Infectious Disease Society. Can Med Assoc J. 1990;142(11):1209-12.

34. Mosca A, Summanen P, Finegold SM, et al. Cellular fatty acid composition, soluble-protein profile, and antimicrobial resistance pattern of Eubacterium lentum. J Clin Microbiol. 1998;36(3):752-5.

\section{Publisher's Note}

Springer Nature remains neutral with regard to jurisdictional claims in published maps and institutional affiliations.
Ready to submit your research? Choose BMC and benefit from:

- fast, convenient online submission

- thorough peer review by experienced researchers in your field

- rapid publication on acceptance

- support for research data, including large and complex data types

- gold Open Access which fosters wider collaboration and increased citations

- maximum visibility for your research: over $100 \mathrm{M}$ website views per year

At BMC, research is always in progress.

Learn more biomedcentral.com/submissions 